\title{
Safe development of coal mine enterprises based on Endogenous Growth Theory
}

\author{
X. J. Li \\ College of Resources \& Safety Engineering, \\ China University of Mining \& Technology (Beijing), China \\ and Henan Polytechnic University, China
}

\begin{abstract}
Securing a safe environment is a big issue for workplaces to tackle. Among the casualties in industries of all kinds, accidents in coal mines are the most serious. Starting from the angle of economics, Endogenous Growth Theory was used as the analysis tool in this paper in the hope of finding some solutions to eliminate hazardous elements in coal mines. Based on the analysis, coal enterprises' safe and steady development must rely on human resources and staff development. As coal enterprises are highly dangerous, staff can ensure safe production of coal mines. Without qualified staff, safety cannot be guaranteed. Then, from the angle of trainers, including government, education departments, and enterprises, and the angle of trainees, including undergraduate students, employees and the public, the paper discusses how individual trainers departments should collaborate with each other to accomplish their duties to cultivate trainees, thus to build a multi-channel system of training staff.
\end{abstract}

Keywords: coal mine safety, Endogenous Growth Theory, multi-channel, human capital.

\section{Introduction}

Among all the accidents that occur in industrial, mining and commercial enterprises, the proportion of coal mine accidents ranks first and catastrophic accidents occur occasionally. In 2006, of all the 12,065 accidents and 14,382 casualties in the industrial, mining and commercial enterprises in China, 2,945 accidents happened in coal mine enterprises which resulted in the death of 4,746 people. This accounted for $24.4 \%$ and $33 \%$ of the total, respectively. From 2002 
to the end of 2006, 188 catastrophic accidents (more than 10 deaths per accident) occurred and, on average, one accident occurs every 4.7 days. China's coal output accounts for nearly $40 \%$ of worldwide coal output; however, the number of deaths in China's coal mines takes up nearly $80 \%$ of global coal mining casualties. Compared with the main coal-producing countries, the death rate per one million tons in China's coal mines is 50 times that of America, 30 times that of Australia and 3 times that of India, and the annual economic loss caused by coal mine accidents reaches up to RMB 30 billion in China. As can be seen from the above, the work safety trend for coal mine enterprises is severe, and safety problems in coal mines are crying out for solutions. It has become an issue of great concern for government agencies at different levels, society and the coal industry, and there is a need to strengthen the safety management of coal mines, reduce coal mine accidents, especially catastrophic accidents, and decrease safety accidents (Huang et al. [1] and Wang [5]).

With respect to the poor state of development in coal enterprises, there have been many discussions between experts from different levels representing various points of view, including personnel quality, law enforcement, technical equipment, management method and safety culture etc, all of which can guide work safety in coal mines. In view of the diversity and complexity of safety problems in coal mines, the paper, based on Endogenous Growth Theory, aims to explore new ways to solve safety problems in coal mine enterprises.

\section{Relationship between work safety and human capital stock level in coal mine enterprises}

Economists, including Romber and Lucas, through absorbing former economic growth ideas and reconsidering the neo-classical growth theory, developed Endogenous Growth Theory in the middle 1980s. According to Endogenous Growth Theory, the long-term economic growth for a country is determined by endogenous variables focusing on progress in knowledge or technologies and human capital, etc. Lucas [2] introduced human capital as a production factor into the economic production function directly, that is, the external influence of human capital was greatly emphasized. He thought that economic growth came from accumulation of human capital. There would be no economic growth without accumulation of human capital and different accumulation rates of human capital were the main reason for explaining different economic growth rates and income disparity across countries. Romer [4] brought forward the knowledge spillover model. He held that endogenous technical progress was the only source for economic growth, and the level of human capital stock would affect the ability of knowledge innovation and simulation as well as the ability of new technology absorption. This would further affect the technical progress rate to promote economic growth, and the impact of human capital stock on economic growth was fully emphasized. Romer [4] insisted that the external effects of human capital (average human capital level of social labor) play a core 
role, and such, effects would spread from one individual to another and contribute to the productivity of each production factor, so that the production can acquire increasing returns to scale. However, it was the increasing returns resulting from external effects of human capital that made human capital become the engine of growth (Lucas [2]). The same principle also applied to the coal mine enterprises. The conditions of work safety are in direct proportion to economic growth of enterprises, and economic growth is impossible for the enterprises without paying attention to safety. Therefore, the conditions of work safety in coal mines can be regarded as an economic growth level for coal mine enterprises, and the relationship between safety and human capital is illustrated in Figure 1.

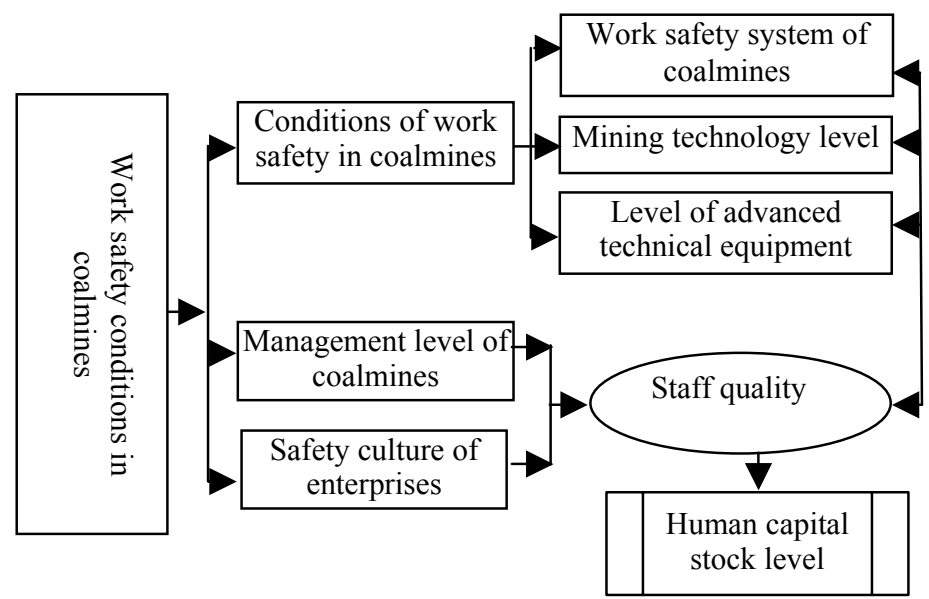

Figure 1: Relationship between work safety and human capital stock level in coal mine enterprises.

As we can see from Figure 1, there are many factors influencing work safety in coal mines, such as conditions of work safety, which also include reasonable work safety systems, mining technology level, advanced level of technical equipment, high management level of coal mines and good enterprise culture on safety, etc. The mentioned factors are dependent on staff quality in the coal mine enterprises. According to Endogenous Growth Theory, staff quality is the human capital stock level of coal mine enterprises. Therefore, the core of work safety in coal mine enterprises is to improve staff quality and increase the human capital stock level. That is, the fundamental factor is the staff, with high quality among these factors. Table 1 indicates the relationship between the proportion of technical personnel and the death rate per one million tons in the coal mine enterprises of different ownership in the year 2000, and the table also implies the relationship between work safety and human capital stock level. 
Table 1: $\quad$ Relationship between coal mine accidents and staff quality in China in 2000 .

\begin{tabular}{|c|c|c|c|c|c|}
\hline $\begin{array}{l}\text { Category of } \\
\text { Coal mines }\end{array}$ & Deaths & $\begin{array}{c}\text { Death } \\
\text { Rate per } \\
\text { One Mil. } \\
\text { Tons (\%) }\end{array}$ & $\begin{array}{l}\text { Proportion } \\
\text { of } \\
\text { Technical } \\
\text { staff }(\%)\end{array}$ & $\begin{array}{c}\text { Proportion of } \\
\text { Personnel with } \\
\text { Senior High } \\
\text { School Education } \\
\text { Level or above } \\
\text { (\%) }\end{array}$ & $\begin{array}{c}\text { Proportion of } \\
\text { Personnel with } \\
\text { Junior High School } \\
\text { Education Level or } \\
\text { above }(\%)\end{array}$ \\
\hline Total & 5798 & 5.798 & 1.56 & - & - \\
\hline $\begin{array}{c}\text { Key state- } \\
\text { owned }\end{array}$ & 1004 & 2.01 & 2.7 & 45.5 & 92.7 \\
\hline $\begin{array}{c}\text { Local state- } \\
\text { owned }\end{array}$ & 842 & 4.21 & 0.86 & 22.1 & 78.3 \\
\hline $\begin{array}{l}\text { Town-level } \\
\text { and private }\end{array}$ & 3952 & 9.88 & 0.32 & 12.8 & 32.1 \\
\hline
\end{tabular}

According to an investigation by the State Administration of Work Safety, there are nearly 40 large and medium-sized coal mines (annual output of 5 million tons or above) whose engineering technical personnel (with technical secondary school diploma, technical college diploma or above) number less than 2,000 , only accounting for approx $3 \%$ of their total workforce. In contrast, the proportion exceeds $60 \%$ in developed countries. At present, $94 \%$ of China's coal mines are short of electromechanical professionals, $80 \%$ of coal mines lack mining professionals, the professionals on ventilation and prevention are also in great demand, and $80 \%$ of coal miners are migrant workers. Therefore, it is not difficult to understand the reason why the number of accidents caused by staff accounts for $68-92.4 \%$ of the total accidents, according to the statistic analysis on causes for coal mine safety accidents at both home and abroad. We can say that staff negligence is the major reason for injury and death accidents.

Therefore, the coal mine enterprises shall further perfect the system on promoting human capital accumulation and technical progress and increase investment in human capital and technical research and development, to maintain sustainable, safe and sound development. Even though the most advanced technologies and equipment are introduced, they cannot be brought into full play without talents, and the work safety and sound development of coal mine enterprises cannot be guaranteed. On the one hand, the enterprises shall pay attention to investment in hardware. On the other hand, they shall lay emphasis on the establishment of the multi-channel cultivation system for technological talents and attach importance to talent cultivation, to meet demand and guarantee the work safety in coal mines. 


\section{Staff training system and measures for coal mine enterprises}

To provide a solution to the problem of talent shortage in coal mine enterprises, the government, education department and enterprises - as the training subjects shall collaborate and jointly take measures to establish a multi-channel and diversified staff training or talent cultivation mode. As for the cultivation object, the students, in-service employees and social public shall be considered, to expand the scope of coverage as much as possible. The government, as a control subject, plays an irreplaceable role in strengthening the work safety control and guaranteeing the safety and sound development of coal mine enterprises. In terms of talent cultivation, the government shall provide policy support on relevant student recruitment and formulate favorable policies on talent cultivation for coal mine enterprises. Some policies, such as waiver or reduction of tuition fees for majors in geology and mineralogy, are made to attract more students to enter this field. Moreover, the government shall draw up strict laws and regulations, requiring the coal mine enterprises to carry out regular training and assessment for their in-service employees. "Training" is an important link for enterprises to achieve safe production, but is too often neglected. There are various training methods in attaining this, but the effect should be given more emphasis. The training object should cover all the personnel other than those employees who are only working underground. Training is also required for those who work underground temporarily or occasionally, such as contract workers, scientific research personnel and external personnel, etc. Through training, the enterprises can enhance the operation level of the in-service employees, therefore fully developing and taking advantage of the existing human resources and improving human capital accumulation.

The education institution, being a talent cultivation and output institution, shall pay attention to cooperation with enterprises. The colleges, universities and enterprises can raise funds together and jointly prepare talent cultivation objectives and plans, which is an effective way to cultivate talents required by enterprises. In addition, teachers in colleges and universities who have a high theoretical level but lack practical experience can practice in enterprises, which is propitious for the enterprises to create a good environment and atmosphere of talent cultivation and achieve a win-win situation. With cooperation between colleges, universities and enterprises, and the combination of "production, education and research", the colleges and universities can optimize teaching modes, improve teaching methods, enrich teaching content, strengthen teaching measures, enhance teaching efficiency and cultivate more useful talents for safe and sound development of coal mine enterprises.

The first two conditions are external objective influencing factors for talent cultivation. Coal mine enterprises, as an internal subject for talent cultivation, shall carry out talent cultivation from the following respects: firstly, an effective incentive mechanism shall be established. As Marx said, "Demand is one of 
human natures" [3]. Demand is essential and necessary for the existence of humans, and human activities are driven by demand, which is made to satisfy the demands at different levels on different stages. Therefore, coal mine enterprises shall establish a multi-incentive mechanism, to try to satisfy different requirements and absorb talents effectively. Secondly, in combination with the effective incentive mechanism, the coal mine enterprises shall improve their soft and hard environment, to better retain the introduced talents. For example, the enterprises can provide a good development environment and platform for the introduced talents taking material and humanism into account in order to retain and stabilize talents. In addition, the enterprises shall bring the talents into full play. In a word, the enterprises shall introduce talents, retain talents and make the most of talents.

In recent years, the State has implemented a series of emergency measures and methods:

1. Expanding the scale of professional cultivation in close relation to safety production of coal mine enterprises. For example, the undergraduate colleges and universities have properly expanded the scale of student recruitment on coal mining specialties. The vocational colleges have expanded the scale of talent cultivation on coal mining technology, mine electro-mechanics and mine ventilation and safety.

2. Establish "national professional talent cultivation bases for coal mine enterprises". Rely on common colleges and universities with required qualification, select the specialties with required schoolrunning strength and in close connection with coal mine enterprises, and build them into "national professional talent cultivation bases for coal mine enterprises" through key support. Make use of the driving effect of the bases, and provide demonstration and support for the large and medium-sized coal mine enterprises, institutions and research units as well as relevant colleges and universities' coal mining talent cultivation.

3. Implement "cultivation and training projects for tight skilled talents in the coal industry". The State has selected the scarce specialties on coal mining technology, mine electro-mechanics and mine ventilation and safety among vocational colleges of coal, and implemented the "cultivation and training projects for tight skilled talents in the coal industry". Organize the engineering technical personnel from coal mine enterprises and teachers from vocational colleges to jointly develop talent cultivation plans and relevant curriculums and teaching material, and additionally offer safety curriculums based on teaching plans, so as to accelerate the cultivation of skilled talents urgently required by coal mine enterprises. 
4. Perfect "student recruitment from secondary specialized schools" and "customized" cultivation modes. Carry out advanced admission for the students applying for coal mining-related specialties offered by "national professional talent cultivation bases for coal mine enterprises" and the colleges and universities undertaking "cultivation and training projects for tight skilled talents in the coal industry". Continuously explore and perfect the policies on "student recruitment from secondary specialized schools". Encourage colleges, universities and coal mine enterprises to carry out cooperative school-running, recruit directional students according to the mode of work-study combination, and carry out "customized" cultivation. Allow students to transfer to the coal specialty and train them according to the "customized" cultivation mode.

5. Improve the cultivation quality for coal mining professionals. Relevant colleges and universities shall positively reform teaching content and methods, and strengthen the pertinence of cultivation for coal mining professionals. The undergraduate colleges and universities with required conditions shall add the safety management specialty based on the safety engineering and mining engineering specialties, add the teaching content related to work safety management for the specialties of engineering and management science etc, to cultivate the professionals who are skilled in both technology and management. The vocational colleges of coal shall, based on the demand of work posts in the coal industry, actively make cooperation with coal mine enterprises and cultivate required skilled talents with strong operative ability. Strengthen the link of practical teaching, enhance the construction of practical training bases, increase the students' practice time in coal mine enterprises and improve their practical ability.

6. Increase the investment. Provide fund support for the cultivation of coal mining professionals, gradually increase the level of fund appropriation per student of coal mining-related specialties, and take scholarships for coal mining-related specialties into account while formulating scholarship management regulations and methods for tough specialties.

7. Set up special funds for the construction of coal mining-related specialties and actively absorb enterprise social capital.

8. Carry out regulatory, normalized and standardized technical safety training for in-service employees. Establish multi-level coal mine safety training organizations, and achieve hierarchy management for coal mine safety training. Implement the safety qualification certificate 
system and training system for all employees, and those who do not pass the training or obtain a safety qualification certificate shall not take up a post. Formulate corresponding training management methods for the training of common workers.

9. Carry out assessment and certification in strict compliance with national regulations for the technical safety training of legal representatives, main responsible persons and special types of workers in coal mine enterprises. Place particular emphasis on strengthening the qualification training for the production management personnel and special types of workers in small-scale coal mine enterprises, establish the compulsory training system and ensure only those who pass the training can take up a post.

Through emergent and effective implementation of the aforementioned measures, it preliminarily alleviates the talent shortage for coal mine enterprises within a short period, improves the low level of safety knowledge for the employees and plays an important role for the work safety of coal mines.

\section{Conclusion}

The survival and development of enterprises are dependent on utilization and exploitation of human resources $(\mathrm{Xu}[7])$. Therefore, in order to guarantee safety and sound development of coal mine enterprises; laying stress on investment in safety facilities and equipment is insufficient. From the angle of economics and based on analysis and exploration on Endogenous Growth Theory, it is crucial that more attention be focused on talent cultivation and human capital accumulation. Hence, establishing a multi-channel talent cultivation system through the cooperation between the government, education department and enterprises, expanding the routes of talent cultivation, training of more excellent individuals suitable for coal mine enterprises, solving the talent shortage problem and further guaranteeing the safe and sound development of coal mine enterprises are required.

\section{References}

[1] Huang, S.C., Zhou, X.Q. \& Zhang, B.C., Analysis on work safety and economic development. Coal Journal, 30(5), pp. 580-584, 2005.

[2] Lucas, R. On the Mechanics of Economic Development. Journal of Monetary Economics, 22: pp. 3-42, 1988.

[3] Marx, Karl and Frederick Engels, Beijing: People's Press, Vol..3, pp. 271350, 1995.

[4] Romer, P.M. Endogenous technological change. Journal of Political Economy, 98(5), Part ii: pp. 71-102, 1990. 
[5] Wang, J., Analysis and measures on coal mine safety management. China Work Safety Science and Technology, 2(1), pp. 69-72, 2006.

[6] Wang, Q.J., Reasons and solutions for the short of qualified staff in coal mines. Modern Enterprises Education, 1, pp. 32, 2006.

[7] $\mathrm{Xu}, \mathrm{D} . \mathrm{S} .$, Management system Integration of quality, environment and occupational safety\& health. China Safety Science Journal, 12(1), pp. 9-13, 2002. 